East African Medical Journal Vol. 80 No 4 April 2003

METABOLIC CONTROL OF TYPE 2 DIABETIC PATIENTS COMMONLY TREATED WITH SULPHONYLUREAS IN A DEVELOPING COUNTRY

C.E. Ezenwaka, BSc, MSc, MPhil, PhD, Unit of Pathology and Microbiology, Faculty of Medical Sciences, The University of the West Indies, St. Augustine, Trinidad, West Indies

\title{
METABOLIC CONTROL OF TYPE-2 DIABETIC PATIENTS COMMONLY TREATED WITH SULPHONYLUREAS IN A DEVELOPING COUNTRY
}

\author{
C.E. EZENWAKA
}

\begin{abstract}
Background: Previous reports suggest that currently available drugs used in the treatment of type 2 diabetes do not sustain glycaemic control.

Objective: To assess metabolic control in type 2 diabetic patients predominantly treated with sulphonylurea drugs at primary care clinics in a developing country.

Design: Descriptive.

Setting: Two primary care clinics in Trinidad, West Indies.

Subjects: One hundred and seventy nine (117 females and 62 males), randomly selected, type 2 diabetic patients.

Protocol: Body weight, height, blood pressure (BP), waist and hip circumferences were measured and fasting blood samples taken for glycated haemoglobin $\left(\mathrm{HbA}_{\mathrm{lc}}\right.$, glucose, insulin and lipids determinations. Fasting insulin and glucose concentrations were used to assess insulin resistance and sensitivity $(\% \mathrm{~S})$ using Homeostasis model assessment (HOMA) method.

Results: Of the 179 patients studied, $87 \%$ of male and $92 \%$ of female patients were treated with sulphonylurea drugs whereas $13 \%$ and $9 \%$ of male and female patients respectively were managed on diet and/or exercise. Female patients had significantly higher prevalence of obesity than males, and despite similar fasting glucose and $\mathbf{H b A}_{\mathrm{Ic}}$, levels, the females and patients of East Indian ethnic group had significantly higher prevalence rates of insulin resistance, hypercholesterolaemia, hypertriglyceridaemia and reduced HDL-cholesterol than the males and patients of African origin respectively.

Conclusion: Consistent with previous reports, the results showed indications of poor metabolic control among the patients particularly females and patients of East Indian ethnic group.
\end{abstract}

\section{INTRODUCTION}

Studies on the pathogenesis of type 2 diabetes have shown that the disorder has a hereditary background $(1,2)$ and often develops on the basis of defective beta-cell function $(3,4)$ and insulin resistance(3-6). Fasting and post-prandial hyperglycaemia in type 2 diabetes develop when the beta cells fail to secrete enough insulin to compensate for insulin resistance(6). Patients with intact beta cell secretory capacity can cope with major insulin resistance by maintaining a sufficiently high rate of insulin secretion with the consequent hyperinsulinaemia(6,7). Thus, efforts in controlling hyperglycaemia in type 2 diabetes involve the use of oral hypoglycaemic agents that stimulate insulin release (sulphonlyurea), improve insulin sensitivity (biguanides and thiazolidinediones) and attenuates the absorption of carbohydrates from the gut (acarbose). Although intensive treatment with sulphonylurea or insulin resulted in $12 \%$ risk reduction in microvascular end-points in the UK Prospective Diabetes Study(8), sulphonylurea drugs minimally improve metabolic control(9). Thus, considering the heterogeneous nature of type 2 diabetes and the poor clinical outcome with presently available drugs, regular evaluation of metabolic parameters and search for more effective drugs should be continuous requirements in the management of type 2 diabetes. It has been suggested that drugs such as the long-acting preparation of glucagon-like peptide-1 (GLP-1) may be a novel approach to the treatment of type 2 diabetes(9). While we await full evaluation of GLP-1 in many populations, the claim that current treatments used in the management of type 2 diabetes do not sustain metabolic control on long-term basis $(9,10)$ should be investigated in different populations, especially in developing countries with limited resources. In this regard, metabolic control in type 2 diabetic patients commonly treated with sulphonylurea was investigated in two primary care clinics in Trinidad, West Indies.

\section{MATERIALS AND METHODS}

Patients: One hundred and seventy nine (117 females, 62 males) consecutive type 2 diabetes patients visiting the Arima and Chaguanas primary care clinics in Trinidad between January 2000 and April 2000 participated in the study. Patients were considered as type 2 diabetic patients if they had been managed 
on oral medication and/or diet/exercise since diagnosis (except on occasions when patients took intravenous insulin to control hyperglycaemia). The research assistants randomly approached the patients and thoroughly explained to them the objectives of the research study as well as the study protocol. All patients were nationals of Trinidad and Tobago, comprising mainly descendants of Africa, India and mixed ethnic groups. The Arima and Chaguanas health clinics were designated primary care diabetes centers covering at least $70 \%$ of diabetes patients in the North West Regional Health Authority (NWRHA) in Trinidad. These centers offer basic diabetes health education to the patients on weekly basis although there is paucity of qualified health educators. The NWRHA is the largest of the four regional health authorities in the country, and Arima and Chaguanas clinics were each providing regular diabetes care clinics twice per week. Furthermore, the NWRHA inhabits people of the two major ethnic groups (African and Indian origin) and is strategically located that the two clinics serve the majority of diabetes patients requiring care in the region. All patients gave informed voluntary consent to participate and our institutional Ethics Committee approved the study protocol.

Study protocol: The patients came to the primary care clinics in the morning after a 12-14hour overnight fast. An overnight fasting state was ascertained by direct questioning and later by checking the plasma samples for evidence of lipaemic clouding. Details of ethnic origin and age were directly ascertained from the patients; waist $(\mathrm{cm})$, at the level of the umbilicus with the patient standing and breathing normally, and hip circumferences $(\mathrm{cm})$, at the level of greatest projection of the buttocks, were obtained by tape measure while weight $(\mathrm{kg})$ and height $(\mathrm{m})$, with healthometer (with scale and metal rule), were measured (in light clothing, without shoes). After 10 minutes rest, systolic (first phase) and diastolic (fifth phase) blood pressures $(\mathrm{sBP}, \mathrm{dBP})$ were taken on the dominant arm in a sitting position, using a standard mercury gauge sphygmomanometer (cuff size $23 \times 22.5 \mathrm{~cm}$, Accoson, England). None of the patients required adjustment of the sphymomanometer cuff, thus the same cuff size was used for all patients. A $10 \mathrm{ml}$ venous blood sample was taken from each patient and put into fluoride (for plasma glucose measurement) and plain (for serum insulin and lipid measurements) tubes. Blood samples were separated within two hours of collection and the plasma or serum stored at $-20^{\circ} \mathrm{C}$.

Definitions for poor metabolic control levels: Metabolic control is defined as poor if total cholesterol (t-Chol) levels $>5.2$ $\mathrm{mmol} / \mathrm{L}$ or low density lipoprotein-cholesterol (LDL-Chol) $>$ $3.37 \mathrm{mmol} / \mathrm{L}$ or triglyceride $(\mathrm{TG})>2.26 \mathrm{mmol} / \mathrm{L}(11)$, or totalcholesterol/HDL-cholestero1 (index of heart disease) $>6$ (12), or $\mathrm{HbA}_{\mathrm{lc}}(\%)$ levels $>7.0(8)$, or body mass index $(\mathrm{BMI})>30 \mathrm{~kg} /$ $\mathrm{m}^{2}(13)$ or serum insulin $>90^{\text {th }}$ percentile $(>267 \mathrm{pmol} / \mathrm{L})$ of the sample population.

Biochemical analysis: The serum insulin level was determined by standard radio-immunoassay method using commercial insulin kits (Coat-A-Count Insulin, Diagnostic Products Corporation, Los Angeles, USA). The sensitivity of the assay was $1.2 \mu \mathrm{IU} / \mathrm{ml}$ with intra- and inter-assay coefficients of variation of $4 \%$ and $6 \%$, respectively. Plasma glucose, serum total cholesterol (T-Chol), triglycerides(Ta) and high density lipoprotein cholesterol (HDL-Chol) concentrations were measured using commercial kits (dry slides) in multi-channel auto-analysers (Johnson \& Johnson Co. Rochester NY 14626, USA). Low density lipoprotein cholesterol (LDL-Chol) was calculated using Friedewald method (14). Glycated haemoglobin $\left(\mathrm{HbA}_{1 \mathrm{c}}\right.$ was measured by an affinity microchromatographic methodology using Helena Glyco-Tek HemeSpec ${ }^{\mathrm{R}}$ plus Spectrophotometer (HemeSpec ${ }^{\mathrm{r}}$ Plus, Helena Laboratories USA). The precision of the $\mathrm{HbAl}_{1 \mathbf{c}}$, measurement was checked using the normal and abnormal quality control samples contained in the assay kits and the intra- and inter-assay coefficients of variation were $1.5 \%$ and $1.8 \%$, respectively.

Data analysis: Results are expressed as mean \pm S.E.M. Insulin resistance (IR), calculated as the product of fasting serum insulin and plasma glucose divided by 22.5 , and insulin sensitivity $(\% \mathrm{~S})$ were assessed using values of fasting serum insulin and fasting plasma glucose concentrations in HOMA-CIGMA Calculator Programme Version 2.00 based on HOMA method(15) (courtesy Dr. J. Levy, Oxford University, London). Fasting hyperinsulinaemic index was derived as the ratio of fasting serum insulin to fasting plasma glucose concentration. Comparisons between and within gender, and between the two major ethnic groups (African and East Indian descents) were performed by Student's t-tests and multiple linear regression analysis using the Statistical Package for the Social Sciences (SPSS) software(16). As appropriate, data not normally distributed were log-transformed to improve distribution. Unless otherwise indicated, $\mathrm{p}$-value $<0.05$ was considered statistically significant.

\section{RESULTS}

Table 1 shows the background characteristics of all the patients. One hundred and seventy nine (125 of East Indian descent, 54 of African origin) with confirmed type 2 diabetes participated in the study. Of the 179 patients, 62 (87.1\%) male and 117 (91.5\%) female patients were treated with sulphonylurea drugs while $12.9 \%$ of males and $8.5 \%$ of females were managed on diet and/or exercise. Male patients were older, smoked more cigarettes and drunk more alcoholic drinks ( $p<0.01)$. Males of East Indian descent had higher prevalence rates of cigarette smoking and consumption of alcoholic drinks than their counterparts of African origin ( $p<0.05)$, whereas, these habits were similar in female patients. Males of African descent had significantly higher systolic BP than their counterparts of East Indian descent ( $p<0.05)$. The levels of fasting plasma glucose, $\mathrm{HbA}_{1 \mathrm{c}}$, triglycerides and LDLcholesterol were similar in male and female patients $(\mathrm{p}>$ 0.05 ), however, female patients had higher $\mathrm{t}$-cholesterol levels (Table 2). Despite similar fasting plasma glucose, female patients had significantly higher levels of fasting insulin and insulin-to glucose ratios $(\mathrm{p}<0.05)$ and lower $\% \mathrm{~S}$ than the male patients (Table 3). Although the fasting plasma glucose and $\mathrm{HbA}_{1 \mathrm{c}}$, levels were similar in the male patients from the two ethnic groups ( $p>0.05)$, male patients of East Indian origin had significantly higher fasting insulin levels and lower \%S compared with patients of African descent $(\mathrm{p}<0.05)$. Similarly, fasting plasma glucose and $\mathrm{HbA}_{1 \mathrm{c}}$, did not differ in the female patients from the two ethnic groups $(\mathrm{P}>0.05)$, yet, female patients of East Indian origin had significantly higher fasting insulin level, insulin-to-glucose ratio, insulin resistance ( $p$ 
$<0.01)$ and lower $\% \mathrm{~S}(\mathrm{p}<0.01)$. Furthermore, female patients of East Indian origin had significantly higher triglyceride and lower HDL-cholesterol levels compared with female patients of African origin $(p<0.01)$. Indeed, age, ethnicity, duration of diabetes, gender and obesity are independent factors that influenced the levels of the biochemical parameters (Table 4).

Overall, females and patients of East Indian origin had higher prevalence rates of the measured metabolic parameters (Table 5).

Table 1

Between and within gender comparisons of background characteristics and treatment distributions of patients in two major ethnic groups

\begin{tabular}{|c|c|c|c|c|c|c|}
\hline \multirow[t]{2}{*}{ Parameter } & \multicolumn{3}{|c|}{ Male } & \multicolumn{3}{|c|}{ Female } \\
\hline & $\begin{array}{l}\text { All males } \\
\mathrm{N}=62\end{array}$ & $\begin{array}{l}\text { African } \\
\mathrm{N}=23\end{array}$ & $\begin{array}{l}\text { Indian } \\
\mathrm{N}=39\end{array}$ & $\begin{array}{l}\text { All females } \\
\mathrm{N}=117\end{array}$ & $\begin{array}{l}\text { African } \\
\mathrm{N}=31\end{array}$ & $\begin{array}{l}\text { Indian } \\
\mathrm{N}=86\end{array}$ \\
\hline Age (years) & $58.8 \pm 1.6^{*}$ & $64.0 \pm 2.6$ & $55.7 \pm \mathrm{L} 1.8$ & $55.1 \pm 1.0$ & $58.8 \pm 2.0$ & $538 \pm 61.2 \mathrm{a}$ \\
\hline $\begin{array}{l}\text { Duration of diabetes (years) } \\
\text { Occupation: }\end{array}$ & $10.3 \pm 1.1$ & $9.8 \pm$ E 1.9 & $10.6 \pm 1.4$ & $8.7 \pm 0.7$ & $10.8 \pm 1.5$ & $8.0+0.8$ \\
\hline - Employed (\%) & $23(37.1)^{* *}$ & $5(21.7)$ & $18(46.2)$ & $19(16.2)$ & $9(29.0)$ & $10(11.6)$ \\
\hline - Not employed (\%) & $9(14.5)^{* *}$ & $3(13.0)$ & $6(15.4)$ & $87(74.4)$ & $15(48.4)$ & $72(83.7) b$ \\
\hline - Retired (\%) & $30(48.4)^{* *}$ & $15(65.2)$ & $15(38.5)$ & $11(9.4)$ & $7(22.6)$ & $4(4.7) b$ \\
\hline Cigarette smoking: & & & & & & \\
\hline - Smoker (\%) & $20(32.3)^{* *}$ & $4(17.4)$ & $16(41.0) \mathrm{a}$ & $6(5.1)$ & $1(3.2)$ & $5(5.1)$ \\
\hline $\begin{array}{l}\text { Alcohol consumption: } \\
\text { - Yes }(\%)\end{array}$ & $23(37.1)^{* *}$ & $5(21.7)$ & $18(46.2) \mathrm{a}$ & $17(14.5)$ & $2(6.5)$ & $15(17.4)$ \\
\hline Treatment & & & & & & \\
\hline - Diet \& exercise & $8(12.9)$ & $2(8.7)$ & $6(15.4)$ & $10(8.5)$ & $6(19.4)$ & $4(4.7)$ \\
\hline - Sulphonylurea (\%) & $54(87.1)$ & $21(91.3)$ & $33(84.6)$ & 107(91.5) & $25(80.6)$ & $82(95.3)$ \\
\hline
\end{tabular}

$* \mathrm{p}<0.05, * * \mathrm{p}<0.01$, for between gender (males vs. females) comparison in two ethnic groups (Africa, India) ${ }^{\mathrm{a}} \mathrm{p}<0.05,{ }^{\mathrm{b}} \mathrm{p}<0.01$, for within gender (males vs. males, and females vs. females) comparisons in two ethnic groups (Africa, India)

Table 2

Between and within gender comparisons of indices of obesity and blood pressure in two major ethnic groups

\begin{tabular}{|c|c|c|c|c|c|c|}
\hline & & Male patients & & Female patient & & \\
\hline Parameter & $\begin{array}{l}\text { All males } \\
\qquad \mathrm{N}=62\end{array}$ & $\begin{array}{l}\text { African } \\
\mathrm{N}=23\end{array}$ & $\begin{array}{l}\text { Indian } \\
\mathrm{N}=39\end{array}$ & $\begin{array}{c}\text { All females } \\
\quad \mathrm{N}=117\end{array}$ & $\begin{array}{l}\text { African } \\
\mathrm{N}=31\end{array}$ & $\begin{array}{c}\text { Indian } \\
\mathrm{N}=86\end{array}$ \\
\hline Weight $(\mathrm{kg})$ & $70.7+1.7$ & $73.8+2.6$ & $68.8 \pm 2.1$ & $70.8 \pm 1.1$ & $73.9 \pm 2.2$ & $69.7 \pm 1.2$ \\
\hline Height $(\mathrm{cm})$ & $1.7 \pm 0.01$ & $1.7 \pm 0.01$ & $1.7 \pm 0.02$ & $1.6+0.01$ & $1.6 \pm 0.01$ & $1.6 \pm 0.01$ \\
\hline BMI $\left(\mathrm{kg} / \mathrm{m}^{2}\right)$ & $24.4 \pm 0.6 * *$ & $24.7 \pm 0.7$ & $24.3 \pm 0.8$ & $28.8+0.4$ & $28.8 \pm 0.8$ & $28.8 \pm 0.5$ \\
\hline Waist circumference $(\mathrm{cm})$ & $92.2 \pm 1.3^{*}$ & $89.6 \pm 2.2$ & $93.7 \pm 1.6$ & $96.1+0.9$ & $95.1 \pm 1.9$ & $96.5: 1 \pm 1.0$ \\
\hline Hip, circumference $(\mathrm{cm})$ & $96.6 \pm 1.7 * *$ & $98.8+1.4$ & $95.3 \pm 2.5$ & $109.5 \pm 0.9$ & $108.9 \pm 1.6$ & $109.7+1.1$ \\
\hline Waist-to-hip ratio & $1.1+0.1$ & $0.9 \pm 0.01$ & $1.2 \pm 0.2$ & $0.88 \pm 0.01$ & $0.87 \pm 0.01$ & $0.88 \pm: 0.01$ \\
\hline Systolic BP (mmHg) & $137.7+2.8$ & $145.2 \pm 5.4$ & $133.0+3.0(\mathrm{a})$ & $139.4 \pm 1.9$ & $142.1 \pm 3.5$ & $138.4 \pm 2.2$ \\
\hline Diastolic BP (mmHg) & $83.4 \pm 1.7$ & $84.2=3.0$ & $82.9 \pm 2.0$ & $84.0+1.3$ & $87.2 \pm 2.0$ & $82.8 \pm 1.6$ \\
\hline
\end{tabular}

${ }^{*} \mathrm{p}<0.05, * * \mathrm{p}<0,01$, for between gender (males vs. females) comparison in two ethnic groups (Africa, India)

${ }^{\mathrm{a}} \mathrm{p}<0.05,{ }^{\mathrm{b}} \mathrm{p}<0.01$, for within gender (males vs. males, and females vs. females) comparisons in two ethnic groups (Africa, India) 
Table 3

Between and within gender comparison of plasma glycaemia, insulin sensitivity and other biochemical profile of the patients in two major ethnic groups

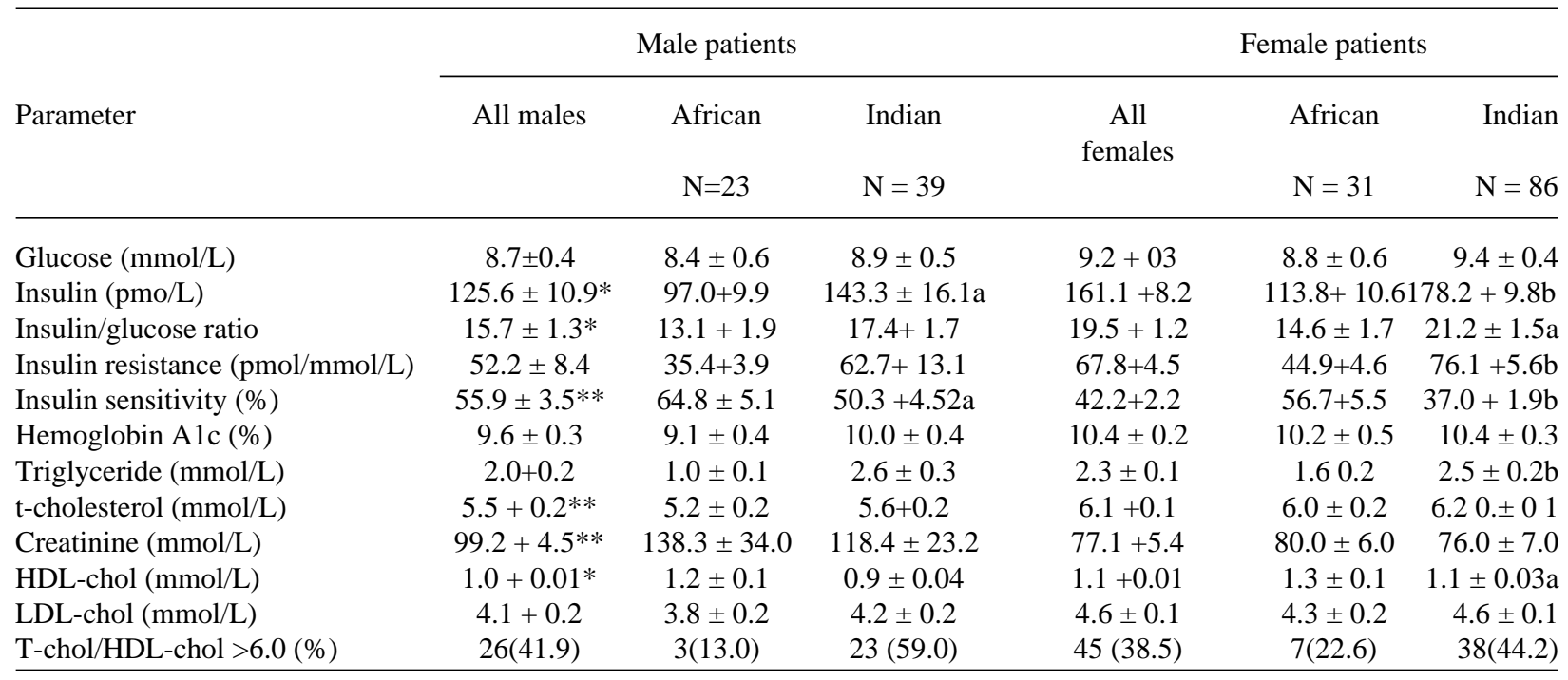

$* \mathrm{p}<0.05, * * \mathrm{p}<0.01$, for between gender (males vs. females) comparison in two ethnic groups (Affica, India)

${ }^{\mathrm{a}} \mathrm{p}<0.05,{ }^{b} \mathrm{p}<0.01$, for within gender (males vs. males, and females vs females) comparisons in two ethnic groups

(Africa, India)

Table 4

Multiple linear regression analysis showing the influence of age, duration of diabetes, sex, ethnicity, BMI, And W/H ratios to the levels of plasma glycaemia, serum lipids and insulin resistance indices

\begin{tabular}{|c|c|c|c|c|c|c|}
\hline \multirow[b]{2}{*}{ Dependent factor } & \multirow[b]{2}{*}{ Age\# } & \multicolumn{5}{|c|}{ Independent factors\# } \\
\hline & & Duration\# & Sex\# & Ethnicity\# & BMI\# & $\mathrm{W} / \mathrm{H}$ ratio\# \\
\hline Glycated haemoglobin & $-0.29 * *$ & $0.21 * *$ & 0.09 & 0.04 & 0.00 & -0.07 \\
\hline Glucose & $-0.34 * *$ & $0.30 * *$ & 0.01 & 0.01 & 0.05 & -0.09 \\
\hline Insulin & -0.08 & 0.07 & 0.04 & $0.28 * *$ & $0.34 * *$ & $0.14^{*}$ \\
\hline Insulin/glucose ratio & 0.07 & -0.13 & 0.09 & $0.21 * *$ & $0.19^{*}$ & $0.26 * *$ \\
\hline Insulin resistance & $-0.19 *$ & $0.24 * *$ & -0.02 & $0.22 * *$ & $0.30 * *$ & 0.02 \\
\hline Insulin sensitivity & 0.04 & -0.06 & -0.10 & $-0.31 * *$ & $-0.35^{* *}$ & -0.11 \\
\hline T-cholesterol & 0.01 & 0.05 & $0.16^{*}$ & 0.11 & 0.10 & -0.09 \\
\hline HDL-cholesterol & -0.06 & 0.00 & $0.18^{*}$ & $-0.40 * *$ & 0.02 & -0.05 \\
\hline LDL-cholesterol & 0.04 & 0.04 & 0.10 & 0.15 & 0.13 & -0.10 \\
\hline Triglyceride & -0.06 & 0.02 & 0.08 & $0.30 * *$ & -0.09 & 0.05 \\
\hline Creatinine & 0.03 & 0.13 & -0.13 & -0.03 & -0.12 & -0.03 \\
\hline
\end{tabular}

$* \mathrm{p}<0.05, * * \mathrm{p}<0.01$. Regression coefficients\#

\section{DISCUSSION}

The study showed high prevalence rates of obesity, poor glycaemic control and dyslipidaemia (hypercholesterolaemia, hypertriglyceridaemia, high LDLcholesterol and reduced HDL-cholesterol) among the patients commonly treated with sulphonylurea. This poor metabolic control vary between gender and between ethnic groups and is further discussed.
Anthropometric indices: The finding of higher prevalence rate of obesity in female patients than males reflects the pattern of obesity in many developing countries where obesity is a major public health problem contributing to cardiovascular risk in female subjects (17-19). Indeed, obesity, whether central or truncal, is associated with metabolic syndrome, which includes cardiovascular risk factors such as diabetes, dyslipidaemia and high blood pressure $(6,7)$. Thus, in this study, body mass index was 
Table 5

Prevalence rates of metabolic parameters measured

\begin{tabular}{|c|c|c|c|c|c|}
\hline & & \multicolumn{2}{|c|}{ Gender } & \multicolumn{2}{|r|}{ Ethnicity } \\
\hline & & Male $(\%)$ & Female $(\%)$ & African (\%) & Indian $(\%)$ \\
\hline Obesity; BMI & $>30 \mathrm{~kg} / \mathrm{m}^{2}$ & $10(16)$ & $45(39) * *$ & $11(21)$ & $44(35)$ \\
\hline Haemoglobin AIc. & $>7.0 \%$ & $52(85)$ & $100(89)$ & $43(84)$ & 109(89) \\
\hline Total-cholesterol & $>5.2 \mathrm{mmol} / \mathrm{L}$ & $33(53)$ & $88(75)^{* *}$ & $29(54)$ & $92(74) * *$ \\
\hline Triglycerides & $>2.26 \mathrm{mmol} / \mathrm{L}$ & $15(25)$ & $40(35)$ & $4(7)$ & $51(42)^{* *}$ \\
\hline LDL-cholesterol & $>3.37 \mathrm{mmol} / \mathrm{L}$ & $42(69)$ & $98(84)^{*}$ & $36(67)$ & $104(84)^{* *}$ \\
\hline HDL-cholesterol & $<0.91 \mathrm{mmol} / \mathrm{L}$ & $27(44)$ & $26(22)^{* *}$ & $8(15)$ & $45(36)^{* *}$ \\
\hline Insulin (> 90th percentile) & $>267 \mathrm{pmol} / \mathrm{L}$ & $3(5)$ & $14(12)$ & $0(0)$ & $17(14)^{* *}$ \\
\hline
\end{tabular}

$* \mathrm{p}<0.05, * * \mathrm{p}<0.01$ for gender and ethnic comparisons

found to be an important factor influencing insulin sensitivity among the patients indicating that efforts towards controlling obesity in developing countries should be encouraged in order to stem the tide of increasing prevalence of metabolic syndrome. Indeed, obesity or overweight is one of the modifiable risk factors for diabetes that could be minimised through lifestyle changes. For instance, two recently concluded clinical trials in Finland and the United States showed that diabetes risk was reduced by $58 \%$ through intensive lifestyle modification intervention in glucoseintolerant subjects $(20,21)$.

Poor glycaemic control: One of the primary goals in the management of type 2 diabetes is the control of fasting and postprandial hyperglycaemia. The present finding of poor glycaemic control, similar in male and female patients irrespective of ethnic origin, appears to support the previous claim that currently available drugs for treatment of type 2 diabetes do not sustain glycaemic control on long-term basis $(9,10)$. Reviews of recent epidemiological studies suggest that fasting and postprandial blood glucose might be independent risk factors for developing cardiovascular disease(22). In this regard patients in the present study might be at risk of microvascular and macrovascular complications of type 2 diabetes(23). However, it should be noted that classical cardiovascular risk factors are not significantly influenced by the levels of plasma glycaemia in this population(24). But since there is no glycaemic threshold at which microvascular and macrovascular complications in diabetes are completely prevented(23), efforts towards tight glycaemic control should remain an important aspect of diabetes management. Even then, it should be noted that blood glucose control is difficult with advancing age due to the well known deterioration in glucose handling in the elderly(25). Additionally, given that the majority of the patients were retired or unemployed (Table 1), socioeconomic factors might have contributed to the poor glycaemic control. For example, in these clinics, prescribed medications unavailable in the public sector had to be obtained privately and patients' compliance in this regard would remain doubtful. It is therefore advocated that females and patients of East Indian ethnic group should be particularly targeted.
Dyslipidaemia and insulin resistance: It is known that hypertriglyceridaemia as seen here, predisposes patients with type 2 diabetes to increased risk of atherosclerosis due to the highly atherogenic, small dense, LDL particle that is often predominant in hypertriglyceridaemic states(26). This atherogenic risk is again higher in female patients and patients of East Indian origin; these two groups had higher cluster of elevated levels of lipid parameters than males and patients of African origin respectively. Although fasting hyperinsulinaemia and insulin resistance are constant pathogenic mechanism in type 2 diabetes $(6,7)$, insulin resistance is also associated with age and obesity, and with long standing diabetes, continued tissue insulin resistance gives rise to lipid abnormalities such as hypertriglyceridaemia. The disproportionate cluster of cardiovascular risk factors (hypercholesterolaemia, obesity, hypertriglyceridaemia, hyperinsulinaemia, elevated LDL cholestesterol) around the female patients and patients of East Indian origin is consistent with previous reports in this population $(27,28)$. It would appear that the higher CVD risk in females than males might be related to the higher prevalence of obesity in females than males (Tables 2 and 5), a finding previously reported in non-diabetic healthy African subjects(18). However, the cardiovascular risk of the male patients might be exacerbated due to their comparatively higher prevalence of cigarette smoking, a habit known to aggravate insulin resistance in patients with type 2 diabetes(29).

Although the efficacy or choice of drug treatment is important in the management of diabetic patients, it should be noted that metabolic control in type 2 diabetic patients visiting primary care clinics in developing countries is challenging. Factors such as patients' compliance to drug prescription, low socioeconomic status, inadequate or unavailable diabetes education and limited laboratory facilities are important limiting factors that contribute to poor metabolic control. Additionally, the beliefs of healthcare providers regarding tight glucose control could affect patients' metabolic control. For instance, a recent study showed that patients whose physicians stressed more aggressive glucose targets achieved lower $\mathrm{HbA}_{\mathrm{Ic}}$. values 
and reduced rates of complications than patients whose physicians set higher glycaemic goals(30). In conclusion, it is recognised that there is unequal gender and ethnic representation in the study, which is a reflection of the pattern of diabetes prevalence and general uptake in the primary care setting in this population(27,28). Again, although we assessed insulin sensitivity with a lessrecognised technical method, HOMA, results obtained with this method was comparable with other established techniques(31). These two limitations notwithstanding, the study showed that patients with type 2 diabetes, particularly females and patients of East Indian origin had poor control of metabolic parameters measured. Improved strategies for patients management, targeted at obesity in female patients, need to be instituted at primary care setting.

\section{ACKNOWLEDGEMENTS}

This study was supported through Research Grant from the University of the West Indies, Trinidad. Many thanks to Risha Kalloo, Aldrick Sandy and members of staff of Lifestyle Disease Clinics, Arima and Chaguanas for providing technical and professional assistance.

\section{REFERENCES}

1 Barnett, A.H, Effo, C, Leslie, R.D. and Pyke, D.A. Diabetes in identical twins: a study of 200 pairs. Diabetologia. 1981; 20:87-93.

2. Newman, B., Selby, J.V., King, M.C., Slemenda, C., Fabsitz, R. and Friedman, G.D. Concordance for type 2 (NIDDM) diabetes in male twins. Diabetologia. 1987; 30:763-768.

3. Weir, G.C. Non-insulin dependent diabetes mellitus: interplay between B-Cell inadequacy and insulin resistance. Am. J. Med. 1982; 73:461-464.

4. Olefsky, J.M., Kolterman, O.G. and Scarlett., J.A. Insulin action and resistance in obesity and NIDDM. Am. J. Physiol. 1982; 243:E15-E30.

5. DeFronzo, R.A., Simmonson, D. and Ferrannini, E. Hepatic and peripheral insulin resistance: a common feature of type 2 (non-insulin dependent) and type 1 (insulin dependent) diabetes mellitus. Diabetologia. 1982; 23:313 - 319.

6. Reaven, G.M. Role of insulin resistance in human disease. Diabetes. 1988; 37:1595-1607.

7. DeFronzo, R.A. and Ferrannini E. Insulin resistance: a multifaceted syndrome responsible for NIDDM, obesity, hypertension, dyslipidaemia and atherosclerotic vascular disease. Diabetes Care. 1991; 18:173-194.

8. United Kingdom Prospective Diabetes Study (UKPDS) Group. Intensive blood glucose control with sulphonylurea or insulin compared with conventional treatment and risk of complications in patients with Type 2 diabetes (UKPDS 33). Lancet. 1998; 352:837-853.

9. Efendic, S. GLP-1 as a therapeutic approach in Type 2 diabetes. Diabetes Rev Int. 1998; 7:2-5.

10. Florkowski, C.M. Outcomes of Type 2 diabetes. Diabetes Rev. Int. 1998; 7:6-8

11. The Expert Panel. Report of the National Cholesterol Education Programme. Expert Panel on detection, evaluation and treatment of high blood cholesterol in adults. Arch. Intern. Med. 1988; 148:36-69.

12 Castelli, W.P., Abbot, R.D. and McNamara, P.M. Summary estimates of cholesterol used to predict coronary heart disease. Circulation. 1983; 67:730-734.
13. World Health Organization Working Group. Use and interpretation of anthropometric indicators of nutritional status. WHO Bulletin. 1986; 64:929-941.

14. Friedwald, W.T, Levy, R.I. and Fredrickson, D.S. Estimation of the concentration of low- density lipoprotein in plasma without use of preparative ultracentrifuge. Clin. Chem. 1972; 18:499-502.

15. Matthews, D.R, Hosker J.P., Rudenski, A.S., Naylor, B.A., Treacher D.F. and Turner, R.C. Homeostasis model assessment: insulin resistance and B-cell function from fasting plasma glucose and insulin concentrations in mail.Diabelologia. 1985; 28:412-419.

16. SPSS for Windows. User's Guide, New York: McGraw-Hill. 1999.

17. Gurney, M. and Gorstein, J. The global prevalence of obesity - an initial overview of available data. World Hlth. Statis $Q$. 1988; 41:251-254.

18. Ezenwaka, E.C., Akanji, A.O., Akanji, B.O., Unwin, N.C. and Adejuwon, C.A. The Prevalence of insulin resistance and other cardiovascular disease risk factors in healthy elderly Southwestern Nigerians. Atherosclerosis. 1997; 128:201-211.

19. Ezenwaka, E.C. and Davis, G. Increased cardiovascular risk factors in newly diagnosed type 2 diabetic patients in a primary health care center in Trinidad. Diabetes Res. Clin. Pract. 2000; 50:137-145.

20. Tuomilehto, J., Lindstrom, J., Eriksson, J.G. et al. Prevention of type 2 diabetes by changes in lifestyle among subjects with impaired glucose tolerance. N. Engl. J. Med. 2001; 344:13431350.

21. National Institute of Diabetes and Digestive and Kidney Diseases (NIDDK). Diet and exercise dramatically delay type 2 diabetes, diabetes medication metformin also effective. NIDDK Fact Sheet Monday. August 2001; 6.

22. Bonora, E. and Muggeo, M. Post-prandial blood glucose as a risk factor for cardiovascular disease in type 11 diabetes: the epidemiological evidence.Diabetologia. 2001;44:2107-2114.

23. Stratton, I.M., Adler, A.I., Neil, H.A. et al. Association of glycaemia with macrovascular and microvascular complications of type 2 diabetes (UKPDS 35): prospective observational study. Brit. Med. J. 2000; 321:405-412.

24. Ezenwaka, C.E. and Offiah, N.V. Classical cardiovascular risk factors in Trinidadian patients with Type 2 diabetes mellitus are not influenced by the level of plasma glycaemia. West Indian Med .J. 2001; 50:288-292.

25. DeFronzo, R.A. Glucose intolerance and aging: evidence for tissue insensitivity to insulin. Diabetes. 1979; 28:1095-1101.

26. Haffner, S.M., Mykkanen, L., Stern, M.P, Paidi, M. and Howard, B.V. Greater effect of diabetes on LDL size in women than in men. Diabetes Care. 1994; 17:1164-1171.

27. Miller, G.J, Beekles, GL, Maude, G.H. et al. Ethnicity and other characteristics predictive of coronary heart disease in a developing community: principal results of the St James Survey. Trinidad. Int. J. Epidemiol. 1989; 18:808-817.

28. Ezenwaka, C. and Offiah, N.V. Differences in glycemic control and cardiovascular risk in primary care patients with type 2 diabetes in West Indies. Clin. Exp .Med. 2001; 1:91-98.

29. Targher, G., Alberiche M., Zenere, M.B., Bonadonna, R.C. Muggeo, M. and Bonora, E. Cigarette smoking and insulin resistance in patients with non-insulin-dependent diabetes mellitus. J .Clin. Endocrinol Metab. 1997; 82:3619-3624.

30. The QuED Study Group: The relationship between physician' self-reported target fasting blood glucose levels and metabolic control in type 2 diabetes. Diabetes Care. 2001; 24:423-429.

31. Bonora, E., Targher, G., Alberiche, M. et al. Homeostasis Model Assessment closely mirrors the glucose Clamp technique in the assessment of insulin sensitivity: Studies in subjects with various degrees of glucose tolerance and insulin sensitivity. Diabetes Care. 2000; 23:57-63. 